\title{
A METODOLOGIA DE ENSINO DA EDUCAÇÃO FÍSICA ACERCA DAS PROPOSTAS PEDAGÓGICAS DA CULTURA CORPORAL
}

\author{
THE TEACHING METHODOLOGY OF PHYSICAL EDUCATION ABOUT \\ PEDAGOGICAL PROPOSALS OF BODY CULTURE
}

Fernando STORA ${ }^{1}$

Marcelo Jose TAQUES ${ }^{2}$

Gustavo LEVANDOSKI ${ }^{3}$

\begin{abstract}
Resumo: O objetivo do trabalho foi constatar a relevância da Cultura Corporal no processo de ensino aprendizagem na disciplina de Educação Física. A pesquisa se caracteriza como documental e de abordagem qualitativa, por concretizar-se a partir de uma revisão bibliográfica. O trabalho partiu de uma introdução das manifestações históricas da Educação Física de modo geral, até chegar à discussão dos propósitos que a cultura corporal permeia para sua intervenção, obtendo como elemento pertinente, a análise sobre as metodologias que são identificadas em tal objeto de estudo, não se atendo a uma crítica elaborada, mas identificando a importância de se ter um meio de intervenção, partindo de um propósito de reflexão. Podemos perceber por meio da pesquisa que a cultura corporal é de extrema importância para o planejamento do professor, pois, ela auxilia diretamente na formação social dos nossos alunos.
\end{abstract}

Palavras-chave: Cultura Corporal. Educação Física Escolar. Metodologia de Ensino.

\begin{abstract}
The objective of this study was to study the Body Culture in the teaching process in Physical Education. The research is presented as a documentary and a qualitative approach, to be carried out based on a bibliographic review. The job of a presentation of manifestations historical schools of Education, by the objective of the perpetuation of the physical permeates to behavior subject, having a pertinent component, the analysis on the methodologies that are are not Do not worry about an elaborated critic, but identifies the importance of a means of intervention, starting from a purpose of reflection. You can realize what a culture is of utmost importance to the teacher's planning as it is able to help you to graduate.
\end{abstract}

Keywords: Body Culture. Physical School Education. Teaching Methodology.

\footnotetext{
${ }^{1}$ Universidade Estadual do Centro Oeste - UNICENTRO - fernando_stora@ hotmail.com

${ }^{2}$ Docente Universidade federal da Grande Dourados - UFGD - taques18@yahoo.com.br

${ }^{3}$ Docente Universidade federal da Grande Dourados - UFGD - gustavolevandoski@ufgd.edu.br
} 


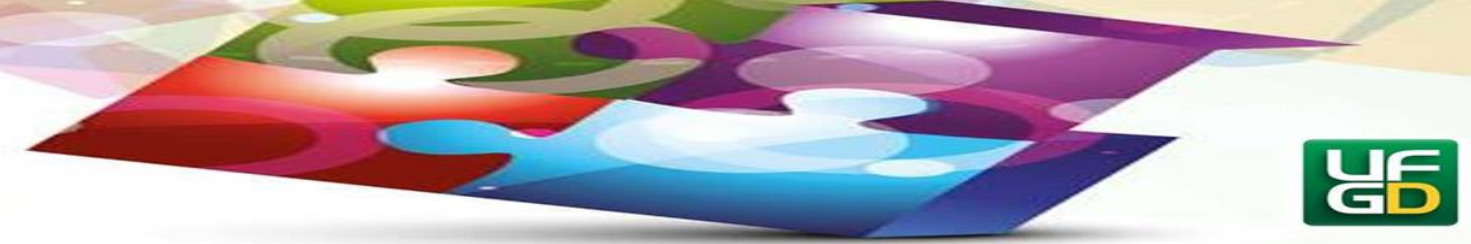

\section{INTRODUÇÃO}

A Educação Física assumiu diferentes papéis durante o seu processo histórico, os quais, sempre estavam atrelados a competência de trabalhar fortemente com a questão da aptidão física e esportiva, durante muito tempo nossa disciplina teve como função formar corpos fortes e saudáveis. Já no processo escolar a Educação Física assumiu uma posição de descobrir e auxiliar a formação de atletas que pudessem competir em um alto nível, nos grandes eventos esportivos.

Porém, atualmente a educação básica expõe novos objetivos a serem alcançados, e para que tais objetivos sejam concretizados, várias teorias e propostas de ensino aparecem constantemente na tentativa de suprir as necessidades dos nossos alunos.

Dentre tais propostas, a Cultura Corporal aparece com uma metodologia de ensino um tanto quanto rejeitada por muitos profissionais da área, devido buscar a sua intervenção a partir da reflexão, e aprofundamento do conhecimento através de um recorte histórico sobre todas as manifestações culturais envolvendo as ações do movimento humano.

Em decorrência, existe um grande embate na efetivação da cultura corporal, considerando que existe um paradigma muito forte da Educação Física estar relacionada somente com a aptidão física e a pratica de esportes, consequente de um longo período sem ser abordado questões relacionadas as dimensões históricas e sociais do movimento.

A partir desse conceito, a metodologia de ensino através da cultura corporal não excluiria a prática de atividades física, nem as modalidades esportivas, mas sim carrega uma proposta de trabalho que busca a reflexão e sistematização do conhecimento de forma historicizada e com uma gradativo aumento de complexidade em seu conteúdo.

Portanto, se considerarmos determinada rejeição por parte de muitos profissionais, a questão é se a cultura corporal seria um objeto de estudo relevante para ser integrada ao planejamento dos professores, já que de certa forma foge as raízes da prática funcional que há tanto tempo vem sendo implantada.

Essa é uma questão que poderá se verificada durante o trabalho, na principal condição de poder mostrar que a Cultura Corporal torna-se relevante para o planejamento docente a partir do momento em que embasa toda a evolução e transformação da Educação Física através da reflexão, fato que fortalece a aprendizagem de tal fenômeno e perpassa a fundamentação 


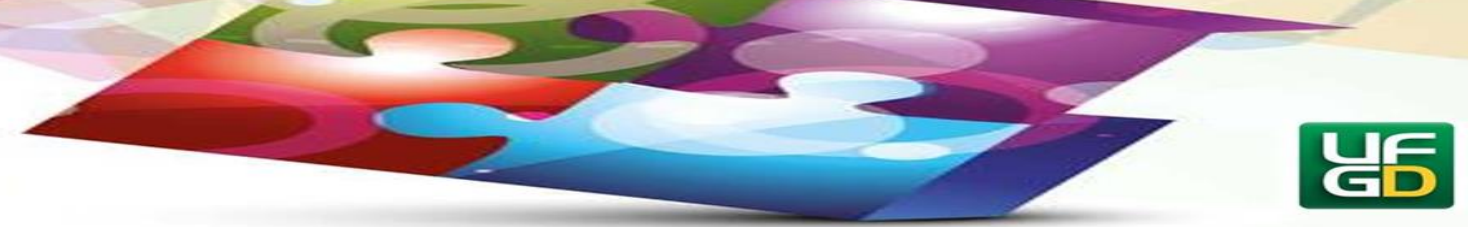

teórico-histórica, intervindo na compreensão e desenvolvimento da prática, e proporcionando ao aluno interagir e transformar o meio o qual está incluso.

Outro aspecto é de que necessitamos de informações acerca de nossa existência, para legitimar cada vez mais nossa disciplina, fazendo da Cultura Corporal um objeto de estudo pertinente, pois, conserva a intervenção e reflexão teórica, buscando entender todas as manifestações históricas culturais que resumem o movimento humano, entretanto, compreendendo a prática como complemento indispensável para o entendimento dos movimentos.

O corpo e o movimento são elementos que retratam a nossa existência, e a partir desse trabalho poderemos acompanhar uma proposta de ensino que visa fundamentar toda nossa cultura, e principalmente que visa formar seres humanos para atuar em qualquer contexto social. Nessa perspectiva, buscamos como propósito demonstrar e discutir qual a relevância da Cultura Corporal no processo de ensino aprendizagem na disciplina de Educação Física, por meio de uma análise de dados bibliográficos.

A partir desse cenário, a Cultura Corporal é um objeto de estudo da Educação Física que busca estabelecer uma ponte de informação entre a teoria e a prática, tomando um enfoque teórico como alicerce de sua intervenção. Portanto é uma ferramenta que pode estar auxiliando a docência para o entendimento da evolução do movimento humano e considerando todas as transformações condizentes à prática da Educação física na escola. Considerando tais situações, é pertinente entendermos seus conceitos e pretensões de trabalho que buscam contextualizar toda a prática, e recondicionar nossos meios de trabalho que voltam objetivos e planejamentos apenas para atividades práticas, assim, poderemos quebrar paradigmas que emergem a Educação Física Contemporânea. Este trabalho está direcionando seus objetivos e conteúdo para os profissionais que atuam na área da Educação Física escolar, na condição de proporcionar a eles a competência de trabalhar com meios reflexivos sobre aquilo que estão propondo nos seus métodos de intervenção. $\mathrm{O}$ acesso à esta proposta de trabalho que está sendo apresentada, tornará possível ao professor assimilar como é propício para o seu planejamento a contextualização de todas as suas atividades práticas, não considerando uma apresentação básica ou apenas exposição dos seus objetivos, mas sim, passando por todo um aprofundamento de como nossa cultura proporcionou a nós estarmos neste estágio de conhecimento a qual nos pertence nesse momento, e é a partir disso que tal trabalho se faz relevante perante aos 


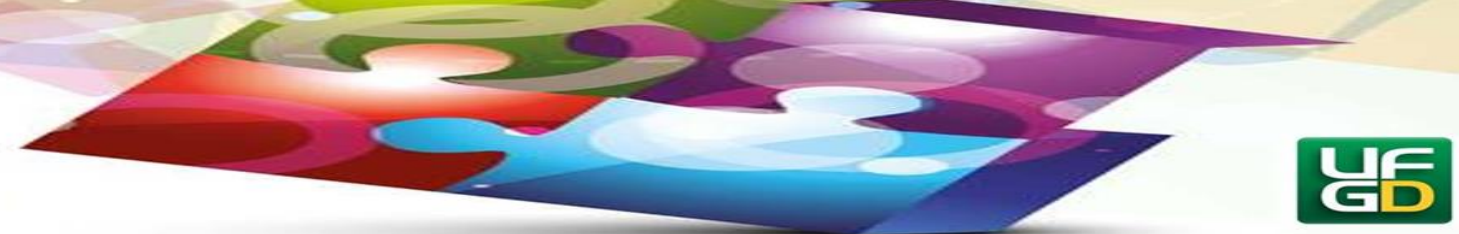

planejamentos de nossa disciplina, pois, viabilizará uma nova fonte de pretensões para aquilo que almejamos para os nossos alunos, e nada mais coerente do que formarmos alunos reflexivos para a sociedade, ainda que, o principal objetivo da educação é formar cidadãos bem amparados para o convívio social.

\section{REPRESENTAÇÕES CULTURAIS ACERCA DA EDUCAÇÃO FÍSICA}

A Educação Física se constitui a partir da necessidade do homem em produzir e aumentar seu poder econômico, no momento em que no século XIX, o progresso vinculado a Revolução Industrial, fez com que o trabalho do homem e a mão-de-obra começasse a ser substituída por uma série de maquinários que a cada momento carregavam mais opções de tecnologia e se desenvolviam de forma desenfreada.

Nessa perspectiva começava uma era capitalista, que visava inconsequentemente o poder exacerbado, e a produção então, passava a ser um protagonista perante a sociedade. Quem se mantinha empregado teria que se sujeitar a cada vez mais cargas exaustivas de trabalho, e se adaptar a implementação constante de novos maquinários, elementos que faziam com que a produção fosse em série, e cada vez mais segmentada, exigindo muito empenho dos trabalhadores.

A partir desse momento, no qual, a carga horária seria muito maior, o maquinário era cada vez mais desenvolvido e em maiores quantidades, e a produção sendo mais dividida e não podendo ser interrompida, a Educação Física passa assumir um papel biológico, que se constituía nas necessidades do capitalismo. Quanto maior a carga horária de trabalho, maior a necessidade de se produzir corpos fortes e saudáveis que viessem suportar horas de trabalho, diante do momento em que o desenvolvimento capitalista se encontrava.

Considerando essa posição física e biológica da Educação Física, a classe burguesa observava cada vez mais a construção de um novo homem integrada à prática da Educação Física, na competência de que ela seria a melhor ferramenta para tal processo. Na condição de que seria ela a produtora de corpos saudáveis, livres da imoralidade, e assumiria também um discurso médico, pedagógico e familiar. 


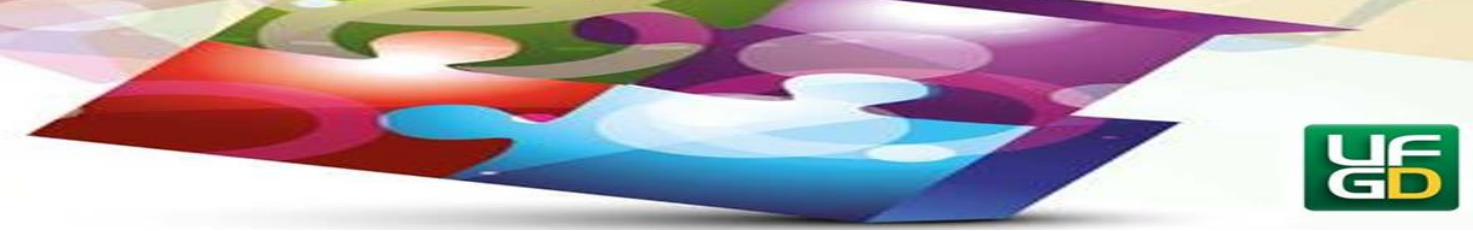

Em um primeiro momento então, o corpo era visto biologicamente, e até mesmo equiparado à máquinas, consequentemente em um segundo momento, as condições viriam a ser melhores, porém, não tanto assim. Competindo a Educação Física a função de ser um instrumento capaz de melhorar não somente a condição física das pessoas, mas sim, capaz de promover melhores condições sociais, uma qualificada educação higiênica e capaz de moralizar hábitos.

Entretanto, essa primeira representação cultural que a Educação Física desempenhou durante o século XIX, estava voltada à construção de um homem que viesse a produzir e retornar lucros para a sociedade capitalista, contemplando principalmente questões físicas e sociais, todavia, quando a Educação Física desembarca no Brasil, com métodos de ensino oriundos da Europa, ela assume uma posição, na qual, também buscava formar corpos saudáveis, porém, na principal função de defender a pátria.

Podemos observar se perpassarmos as dimensões históricas da Educação Física no Brasil, que seus primeiros passos para a educação do corpo e a prática corporal foram voltados para questões técnicas militaristas, contando com o acompanhamento do conhecimento médico. Nesse contexto, surgem as primeiras manifestações da Educação Física referente à prática da atividade física.

Sob a égide de conhecimentos médicos e da instrução física militar, a então denominada ginástica surgiu, principalmente, a partir de uma preocupação com o desenvolvimento da saúde e a formação moral dos cidadãos brasileiros. Esse modelo de prática corporal pautava-se em prescrições de exercícios visando ao aprimoramento de capacidades e habilidades físicas como a força, a destreza, a agilidade e a resistência, além de visar à formação do caráter, da autodisciplina, de hábitos higiênicos, do respeito à hierarquia e do sentimento patriótico.(PARANÁ, 2008, p.38)

Nessa circunstância a Educação Física assumiria um papel extremamente prático, em que tinha suas finalidades voltadas para um aspecto físico e biológico, no qual, seu objetivo era formar corpos que pudessem suportar grandes cargas de treinamento, e estivessem aptos á desempenhar funções militares, além de viabilizar a população hábitos saudáveis. Para Soares (2007, p.11): 


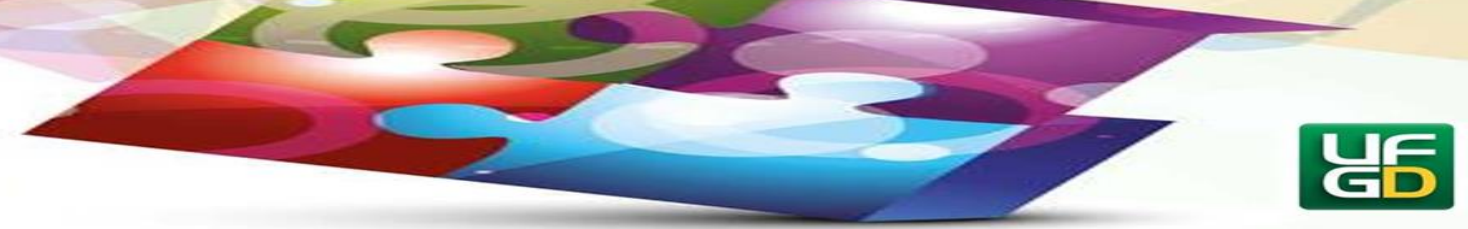

A moralização sanitária na Europa, em meados do século XIX, tratará de reorganizar o espaço de vida dos indivíduos. Seu discurso normativo veiculará a idéia de que as classes populares vivem mal por estarem impregnadas de vícios, de imoralidade, por viverem sem regras. O discurso das classes no poder será aquele que afirmará a necessidade de garantir às classes mais pobres não somente a saúde, mas também uma educação higiênica e, através dela, a formação de hábitos morais. É este discurso que incorpora a Educação Física e a percebe como um dos instrumentos capazes de promover um assepsia social, de viabilizar esta educação higiênica e moralizar os hábitos.

Essas primeiras representações assumidas pela Educação Física, e também vigoradas em tal época no Brasil, são oriundas e alicerçadas em bases e conceitos europeus, que tinham como processo de ensino métodos que defendiam diferentes formas de trabalho e objetos de estudo. Nesse ínterim de reflexões, destaca-se que "o Movimento Ginástico Europeu ocorreu ao longo do século XIX, principalmente na Alemanha, Suécia, Dinamarca e França, que juntamente com o Esporte da Inglaterra, formaram as bases da Educação Física que ainda vigoram no mundo" (BREGOLATO, 2002, p.75).

Em 1929 a proposta é que a Educação Física teria que ser praticada por todos aqueles que residiam em nosso país, e principalmente se tornaria obrigatória sua inserção em todos os estabelecimentos de ensino. Em 1931 a Educação Física adotava um método de ensino, conhecido como Método Ginástico Francês, que englobava características civis, industriais, militares, médicas, e considerava que a educação era um direito de todos para o desenvolvimento social, e também que a ginástica tinha que ser praticada por todos, além de ser um método que se preocupava com a figura feminina devido a sua função de reprodução.

O método ginástico francês, que contribuiu para construir e legitimar a Educação Física nas escolas brasileiras estava fortemente ancorado nos conhecimentos advindos da anatomia e da fisiologia, cunhados de uma visão positivista da ciência, isto é, um conhecimento científico e técnico considerado superior a outras formas de conhecimento, e que deveria ser referência para consolidação de um projeto de modernização no país. (PARANÁ, 2008, p.40) 


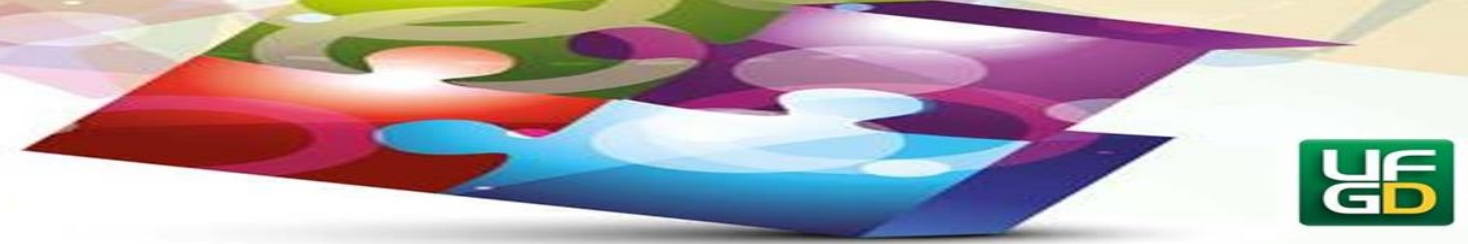

O método ginástico francês viria a ser um dos métodos que influenciariam na legitimação da nossa disciplina, porém outros dois métodos europeus foram relevantes na concepção cultural da Educação Física, além de serem utilizados no mundo todo, seriam eles o Método Alemão e Método Sueco.

$\mathrm{O}$ método alemão representou para a Educação Física um momento em que a metodologia de trabalho teria um caráter extremamente militarista, mecânico e funcional, além de um enfoque nacionalista, organizado pelo estado, o qual contemplava o objetivo que tal método deveria ser praticado por todos, durante todos os dias. No período de 1860 à 1912 seria o método adotado oficialmente pelo exército brasileiro.

A proposta do método sueco seria mais voltada para os âmbitos escolares, de cunho pedagógico, no qual, prezava por professores especializados para trabalharem a ginástica, de forma que atendessem problemas relacionados a postura corpórea das pessoas, proporcionando um atendimento voltado as enfermidades apresentadas na população, além de, optar pela estética, beleza, e a dança na sua concepção de trabalho.

Os métodos ginásticos, e as formas tecnicistas estabeleceram pilares durante muitos anos na prática da educação física, sempre abordando questões relacionadas ao corpo, de forma que atendia aos interesses sempre de terceiros, e não propriamente do praticante. Porém, essa característica seria mantida mesmo com uma provável mudança de foco na década de 1940, que com o fim da $2^{\mathrm{a}}$ Guerra Mundial, começaria um período em que a Educação Física passaria a desempenhar uma função de descobrir e formar atletas para as competições esportivas, e a partir desse momento a prática esportiva estaria sendo implantada nas escolas, na qual, tal prática constantemente ganhava mais ênfase nos espaços escolares, e aos poucos foi consolidando sua hegemonia nas aulas de Educação Física.

Entretanto, o esporte entraria no cenário de forma consolidada devido sua propagação exacerbada nos conceitos de aceitação da sociedade, e o tecnicismo então, entrava em foco novamente nos planejamentos da Educação Física, pois, ficaria na competência dela a descoberta e formação de atletas de alto nível, que pudessem competir em grandes eventos esportivos.

É importante citar que o desenvolvimento da instituição esportiva não se dá independentemente do da Educação Física: condicionam-se mutuamente. A 
esta é colocada a tarefa de fornecer "a base" para o esporte de rendimento. A escola é a base da pirâmide esportiva. É o local onde o talento vai ser descoberto. Esta relação, portanto, não é simétrica. (BRACHT, 1992, p. 22).

Podemos observar até então que a Educação Física assume características tecnicistas e que suas representações culturais acerca do movimento humano estão voltadas para as necessidades das classes dominantes, tanto na formação de corpos fortes e saudáveis para o trabalho e defesa da pátria, quanto na representação de instituições esportivas, nas quais, o esporte em destaque se tornaria um fenômeno predominante, principalmente em espaços escolares.

A presença da Educação Física na prática de alguns contextos históricos ancorou-se em métodos europeus, portanto, em todo momento voltou suas práticas para questões técnicas e fundamentadas na obtenção de resultados, a partir da produção, ou em função do esporte e da prática militarista.

No Brasil, no período de 1850 à 1930 a representação da Educação Física baseou-se em instituições médicas e militares, nas quais, a intervenção obtinha caráter higienista e prezava pela prática familiar, primeiro da elite e na sequencia para toda a população. Sempre a questão a respeito das diferenças raciais ponderava sobre as formas e métodos da prática ser aplicada, afinal, havia uma superioridade da raça branca sobre a raça negra, na qual, boa parte da educação era voltada apenas para a elite, e que cabia a Educação Física, a educação moral, sexual, intelectual e social. E todo o seu contexto partiu das concepções e metodologias advindas da Europa.

Toda essa concepção histórica embasa estudos e novos métodos de ensino que pertence à disciplina de Educação Física, portanto, a cultura da Educação Física em grande período histórico esteve voltado para questões que enfatizavam a prática determinantemente tecnicista e carregada de regras funcionais, as quais, completavam seus objetivos ancorados na necessidade de suprir necessidades fisiológicas diretamente relacionadas as capacidades físicas do ser humano.

Portanto, é um tanto quanto inesperado tentar mudar a concepção histórica da disciplina de Educação Física, uma vez que nesse momento mudando essa concepção, tornaríamos a disciplina reflexiva, afinal não podemos deixar de lado um dos principais conceitos da educação que é formar seres humanos críticos e participantes na sociedade, proporcionando a eles a 


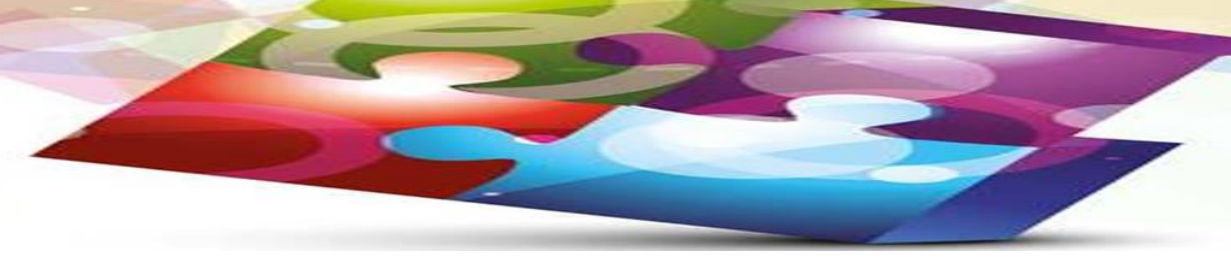

capacidade de solicitar direitos e cumprir deveres, e talvez poderia estar a partir dessa proposta um objeto de estudo que faz com que os alunos se tornem cada vez mais capazes refletir sobre aquilo que instiga o seu conhecimento, objeto de estudo esse chamado de Cultura Corporal.

\section{BASES E CONCEITOS DA CULTURA CORPORAL}

Como pode uma disciplina que tem como principal sujeito de trabalho o corpo em movimento, não abordar em seus conteúdos temáticos contemplando as possíveis transformações que aconteceram durante todo o contexto histórico envolvendo o corpo e o movimento, e a cultura que permeia toda nossa evolução.

A quem conteste a Cultura Corporal. Na defesa de que a Educação Física é uma disciplina inteiramente prática, e que ao consolidar tal objeto de estudo transformaríamos as aulas em um conjunto teórico. A Cultura Corporal não propõe somente a teoria, mais sim a possibilidade de trabalhar concomitantemente a prática e a teoria, deixando de reproduzir movimentos apenas, mais sim entendê-los e repercuti-los a partir de meios que possam contribuir mais ainda para a sua transformação e reprodução partindo de conceitos epistemológicos e históricos culturais.

Não podemos imaginar um ser humano que não seja fruto da cultura e também não podemos imaginar um corpo natural. Portanto, qualquer adjetivo que se associe ao corpo é fruto de uma dinâmica cultural particular, e só faz sentido num grupo específico. O homem só chegou ao seu estágio aluai de desenvolvimento devido a um processo cultural de apropriação de comportamentos e atitudes que, inclusive, foram transformando o seu componente biológico. Não é possível desvincular o homem da cultura. O que o diferencia de outros animais, principalmente, é a sua capacidade de produzir cultura. (DAOLIO, 1995a, p.25)

Não podemos desconsiderar que a Cultura Corporal parte de uma teoria crítica e busca contextualizar as manifestações culturais, na qual, tem como objetivos formar seres sabedores, reflexivos e críticos para a sociedade. Tal teoria é proposta pelas Diretrizes Curriculares Estaduais da Educação Básica de Educação Física (2008, p.45) que entendem a Cultura Corporal como: 


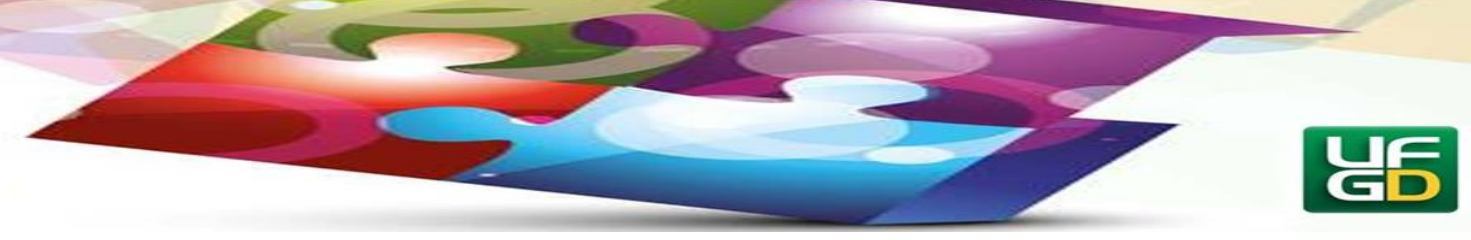

(...) seleção, organização e sistematização do conhecimento acumulado historicamente, acerca do movimento humano, para ser transformado em saber escolar. Esse conhecimento é sistematizado em ciclos e tratado de forma historicizada e espiralada. Isto é, partindo do pressuposto de que os alunos possuem um conhecimento sincrético sobre a realidade, é função da escola, e neste caso também da Educação Física, garantir o acesso às variadas formas de conhecimentos produzidos pela humanidade, levando os alunos a estabelecerem nexos com a realidade, elevando-os a um grau de conhecimento sintético.

A partir desse conceito é que temos que elementar a importância de se estudar as influências históricas, para expor ao aluno as características da realidade, e fazer com que a Educação Física assuma o seu papel de disciplina que tem como objetivo a intervenção social, assim como afirma o autor:

A educação física, segundo nossa ótica, é entendida como uma área de intervenção social, comprometida com a aquisição crítica do saber para o processo de emancipação social. Neste sentido, precisa considerar a cultura como referência para compreensão do corpo e do movimento humano. (MELLO, 2003, p.04)

A Cultura Corporal considera o estudo do movimento a partir de todas as representações históricas, portanto, o objetivo desse conceito não é transformar as aulas considerando apenas a teoria, e deixando de lado o movimento, mais sim conjugar os dois momentos na condição de um completar a carência de conteúdo do outro, sem descaracterizar qualquer conteúdo ou modalidade esportiva.

Outro aspecto que não queremos excluir das aulas de Educação Física com a Cultura Corporal, são as dimensões biológicas e fisiológicas, pois, a proposta pela concepção da Cultura Corporal, não exclui estas dimensões do movimento, porém, contemplá-las diferenciadamente (MELLO, 2003), e tratá-las visando à apropriação de conceitos científicos relativos a elas (VIGOTSKY, 1984 apud MELLO, 2003).

Se considerarmos a história do homem, perceberemos que a partir das necessidades de sobrevivência, surgem os movimentos primários que o permite correr, saltar e consequentemente alimentar-se e defender-se. Assim, percebemos que o movimento esteve e está presente em nosso cotidiano desde a antiguidade, por isso a necessidade da reflexão dos 


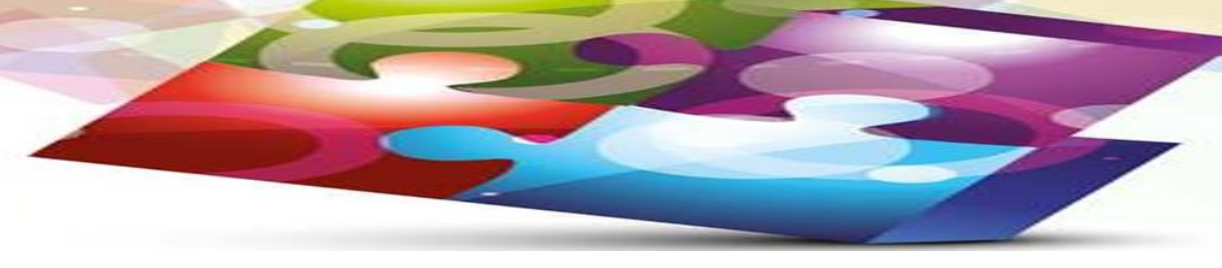

movimentos e o estudo da história dos movimentos do homem. O estudo do movimento nos permite não somente conhecer a história, mas a partir dela, buscar elementos que possamos transformá-la.

Ao falarmos de Educação Física especificamente no Estado do Paraná, percebemos que as Diretrizes Curriculares optam por um objeto de estudo que prioriza a reflexão dos movimentos e a contextualização do aprendizado com a realidade, isso corresponde ao que entendemos por Cultura Corporal.

(...) partindo de seu objeto de estudo e de ensino, Cultura Corporal, a Educação Física se insere neste projeto ao garantir o acesso ao conhecimento e à reflexão crítica das inúmeras manifestações ou práticas corporais historicamente produzidas pela humanidade, na busca de contribuir com um ideal mais amplo de formação de um ser humano crítico e reflexivo, (PARANÁ, 2008, p. 49).

A partir daí entendemos que a Educação Física assim como as demais disciplinas é colaboradora para a formação de um ser crítico e reflexivo, sendo assim um agente na sociedade, e necessitando de uma proposta que proporcione ao aluno o acesso ao conteúdo histórico.

Portanto, a base conceitual da Cultura Corporal compõe um elemento que visa à humanização dos alunos, no sentido de que esse aluno possa estar integrado a uma prática ou um contexto, e que o mesmo desenvolva a capacidade de interagir mediante as representações sociais a ele impostas, e esse aluno possa se portar as variadas situações capaz de recriar possibilidades e transformar o meio a qual está inserido.

No entanto, a Cultura Corporal observada sob o foco do Coletivo de Autores (1992), ainda defende o trabalho da Educação Física por meio de cinco conteúdos que vêm dos grandes temas da Educação Física, tais como: Jogo, Esporte, Luta (Capoeira), Ginástica e Dança, entendendo que estes conteúdos tendem a serem trabalhados de forma sistematizada nos níveis escolares tanto do ensino médio quanto do ensino fundamental.

Baseado em tais conceitos a Cultura Corporal é um objeto de estudo de uma abordagem chamada Crítico-superadora, a qual está vinculada as concepções de uma pedagogia histórico crítica. A abordagem crítico-superadora para Coletivo de Autores (1992) assume algumas características que a tornam uma ferramenta de exposição do conhecimento, reflexão a partir 


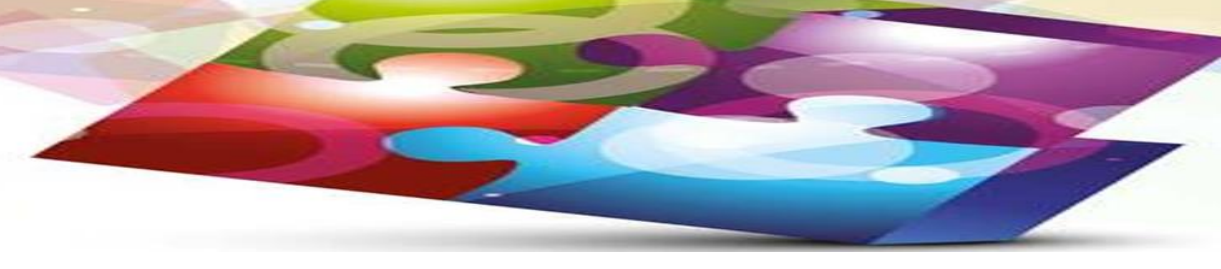

desse conhecimento, e a transformação do mesmo. Assim, "a Abordagem Crítico-superadora, embaza-se no discurso da justiça social no contexto da sua prática. Busca levantar questões de poder, interesse e contestação, faz uma leitura dos dados da realidade a luz da crítica social dos conteúdos" (AZEVEDO, 2001, p.04).

Considerando alguns momentos de reflexão envolvendo a abordagem críticosuperadora podemos subdividi-los em três momentos, ou características. O primeiro busca efetuar o diagnóstico do aluno, através de uma prática social, na qual, os principais elementos a serem considerados, são os conhecimentos prévios do aluno, através da descoberta daquilo que ele já conhece, e buscar identificar qual a realidade desse aluno.

Em conseqüência, o segundo momento, é uma fase determinada judicativa, na qual, intervém sua prática derivado do juízo de valor referente ao aluno, julgando a produção e condição do aluno.

E no terceiro momento configura-se teleológica, porque ocasiona um retorno a prática social, e proporciona ao aluno um meio no qual ele possa transformar aquilo que já foi apresentado e problematizado pelo docente.

Nesta proposta pedagógica, visa-se compreender o movimento humano no âmbito da cultura, abordando-o de forma contextualizada e historicizada, buscando explicitar seus determinantes sociais. Também utiliza conhecimentos relativos ao corpo e ao movimento humano coletivamente produzidos e sistematizados, a fim de ressignificá-los na perspectiva dos interesses das classes dos trabalhadores. (MELLO, 2003, p.05)

Todas essas características apresentadas de certa forma resumem o que a disciplina de Educação Física representa e busca na intervenção de sua prática, derivado de métodos de ensino-aprendizagem que são configurados e ancorados a partir da abordagem críticosuperadora, a qual tem como principal objeto de estudo a Cultura Corporal.

Como podemos observar, as Diretrizes Curriculares Estaduais da Educação Básica de Educação Física (2008) propõe uma Educação Física em que a mesma trabalhe seus conteúdos no sentido de constantemente aumentar o grau de complexidade do conhecimento, porém, 


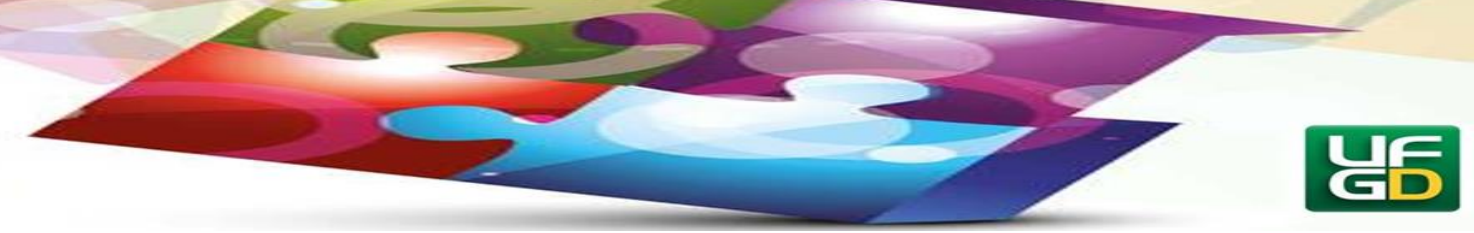

seguindo os ciclos de escolarização que são propostos pela abordagem crítico-superadora (COLETIVO DE AUTORES,1992).

Os ciclos de escolarização estão definidos em quatro etapas e consequentemente organizados da seguinte forma: o primeiro ciclo atinge a faixa etária entre a $1^{\mathrm{a}}$ e $3^{\mathrm{a}}$ séries, que busca organizar o conhecimento. O segundo ciclo passa a trabalhar com a $4^{\mathrm{a}}, 5^{\mathrm{a}}$ e $6^{\mathrm{a}}$ séries, e é o momento no qual tem que ser iniciado a sistematização do conteúdo. O terceiro ciclo busca ampliar o grau de complexidade dos conteúdos e é proposto para a $7^{\mathrm{a}}$ e $8^{\mathrm{a}}$ séries. E no quarto e último ciclo deve enquadrar-se para o ensino médio na condição de proporcionar ao aluno o aprofundamento de tal conhecimento implantado durante o processo de escolarização.

A Educação Física é entendida como sendo uma disciplina que trata do jogo, da ginástica, do esporte, da capoeira, da dança como sendo um conhecimento da cultura corporal de movimento. Busca entender com profundidade o ensinar, onde não significa apenas transferir ou repetir conhecimentos mas criar as possibilidades de sua produção crítica, sobre a assimilação destes conhecimentos, valorizando a questão da contextualização dos fatos e do resgate histórico. (AZEVEDO, 2001, p.04).

Baseado nesse pressuposto é que a Cultura Corporal parte do conceito de organizar e sistematizar o conhecimento historicamente produzido, e principalmente na condição de valorização a contextualização dos fatos, obedecendo assim, a proposta metodológica apresentada por Coletivo de Autores (1992) no sentido de seguir o ciclo de escolarização.

A partir desses processos metodológicos que envolvem a cultura corporal, um dos principais objetivos dessa proposta é o conceito de que tem que haver transformações intelectuais por parte dos alunos, na condição de que os mesmos entendam a sistematização do conteúdo, possam compreender o que é cultura e a sua influência mediante as práticas contemporâneas, e também que possam distinguir e estarem conscientes da realidade a qual estão inseridos, e de alguma forma contribuir para o crescimento social desse meio.

Portanto, as bases e conceitos organizados referentes à Cultura Corporal apontam seus objetos de intervenção para uma prática que proporcione ao aluno ou grupo uma transformação social pertinente, partindo de uma proposta metodológica que vise uma reflexão, na qual, consista em questões sociais, políticas e culturais, contextualizadas acerca de manifestações 


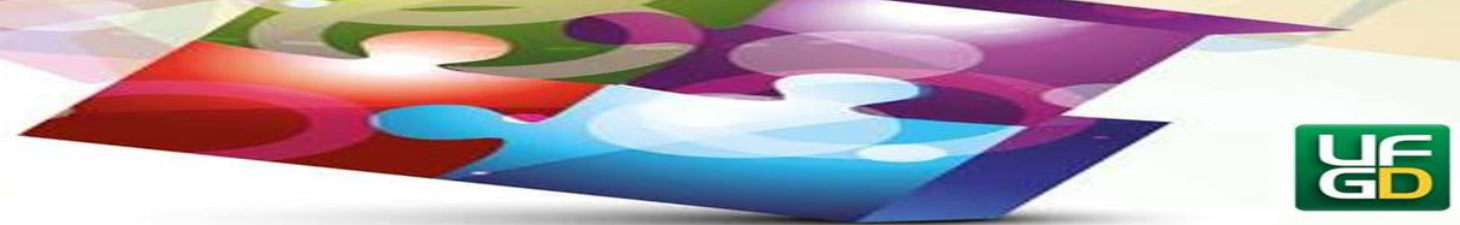

históricas. A Cultura Corporal prevê o estudo dos cinco principais conteúdos na condição de que o conhecimento possa ser significativo e que haja uma consistente transformação social do individuo.

Como já foi apontado, o principal objetivo da educação é oportunizar ao aluno a possibilidade de receber o conhecimento através de disciplinas que determinam campos específicos de estudo e delimitam a sua proposta pedagógica de ensino de acordo com aquilo que entendem como relevante para o crescimento e desenvolvimento social desse aluno, na condição de torná-lo capaz de identificar as diversidades inseridas na sociedade a qual ele pertence. Entre essas disciplinas está inclusa a Educação Física, que por sua vez também propõem em seus planejamentos a formação de seres humanos críticos e reflexivos para a sociedade.

É a partir desse conceito que podemos acompanhar no capítulo a seguir a relevância da proposta de ensino acerca da Cultura Corporal, na proporção de condicionar aos alunos a reflexão sobre temáticas envolvendo a cultura do movimento, e também na legitimação da nossa disciplina enquanto componente curricular.

\section{A CULTURA CORPORAL COMO OBJETO DE ESTUDO RELEVANTE PARA A DISCIPLINA DE EDUCAÇÃO FÍSICA}

O grande confronto para a efetivação da proposta em questão é o embate com pensamentos relacionados à Educação Física como disciplina que tem que vincular somente a técnica e a aptidão física a sua prática, desmembrando o grande objetivo da educação básica que é formar seres críticos para a sociedade, formando cada vez mais seres reprodutores de modelos já impregnados na própria sociedade.

Algumas críticas são atribuídas à Cultura Corporal, relacionando a proposta como uma intervenção que prevê muito discurso social e ideológico e pouca ação motora, além de ter uma metodologia de transformação, a qual é entendida como um meio de descaracterizar uma prática, como por exemplo, adaptar regras para uma modalidade esportiva.

Porém, se faz extremamente relevante o discurso teórico e a contextualização do conhecimento, para que haja o entendimento e contato entre o homem e aquilo que contribuiu para que ele viesse a representar a sua posição ocupada na sociedade de hoje, e isso somente 


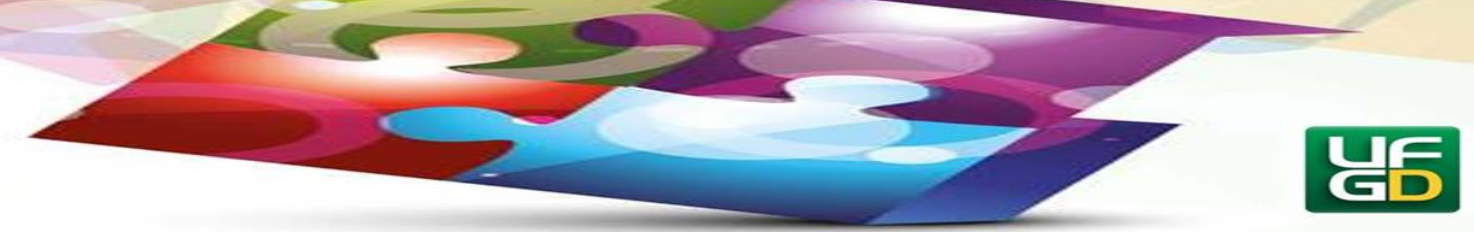

acontece a partir de uma proposta que articule a reflexão acerca dos acontecimentos históricos, não podemos então esquecer que a expressão corporal também pode ser entendida como uma linguagem, e que o homem representa contextos e situações e até mesmo comunica-se através do movimento.

Nessa perspectiva da reflexão da cultura corporal, a expressão corporal é uma linguagem, um conhecimento universal, patrimônio da humanidade que igualmente precisa ser transmitido e assimilado pelos alunos da escola. A sua ausência impede que o homem e a realidade sejam entendidos dentro de uma visão de totalidade. Como compreender a realidade natural e social, complexa e contraditória, sem uma reflexão sobre a cultura corporal humana? (COLETIVO DE AUTORES, 1992, p.42).

A partir dessa indagação, é que não podemos descaracterizar que o movimento humano influencia na nossa prática social, e influenciou em todas as ações da humanidade, considerando que todas as outras disciplinas do currículo escolar trabalham com um conhecimento cientifico universal, a partir de um viés histórico, é importante que a Educação Física também precise de um objeto de estudo que apresente aos alunos aquilo que o corpo e o movimento representaram nos diversos contextos históricos apresentados no presente trabalho até então. Nesse debate "a cultura corporal se manifesta de acordo com o perfil das sociedades. Isso é fato. Por isso as manifestações culturais, inclusive as manifestações de cultura corporal, podem ser qualificadas e classificadas de acordo com o perfil de sociedade que estamos observando" (MERLO, 2006, p.04).

Entretanto, entendendo que o aluno é um sujeito participante na sociedade, a Educação Física que tem como objetivos de produzir o conhecimento ao mesmo tempo que precisa articular a prática funcional com a reflexão, na qual, a contextualização se faz necessária para que o aluno compreenda o seu corpo como um elemento de cultura.

A educação física, segundo nossa ótica, é entendida como uma área de intervenção social, comprometida com a aquisição do saber para o processo de emancipação social. Neste sentido, precisa considerar a cultura como referência para a compreensão do corpo e movimento. (MELLO, 2003, p.04)

A Cultura Corporal tem que ser efetivada para que os alunos compreendam o que o seu corpo produz e produziu, e fazer com que ele entenda os diversos significados da sua existência. 


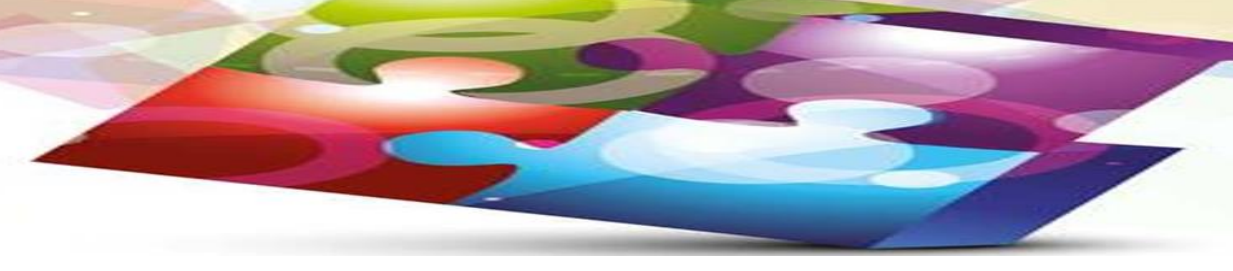

Além de a Cultura Corporal problematizar o corpo e o movimento respaldados em manifestações históricas, tal proposta se torna relevante ao enfatizar em sua metodologia a problematização da realidade em que o sujeito faz parte, no sentido de que o mesmo possa atribuir valor para a prática a qual está realizando, compreendendo e questionando o conhecimento que lhe é atribuído, e fazendo do mesmo uma ferramenta capaz de auxiliá-lo na sua intervenção social, e como argumenta o autor deixar que a prática vá além do fazer corporal.

(...) as práticas corporais que constituem a cultura corporal são fruto do trabalho, da atividade produtiva humana com vistas à satisfação de necessidades. O reconhecimento dessas práticas como sociais implica vivenciá-las para além do fazer corporal, englobando a reflexão sobre o seu valor e intenção. (OLIVEIRA, 2005, p.132)

A prática de atividades físicas não podem ser deixadas de lado nas aulas de Educação Física, pois, elas estão presentes desde muito tempo, porém, essas práticas devem ser trabalhadas juntamente com a reflexão e entendimento sobre quais são os elementos que fundamentaram e deram base para que essa prática estivesse no atual estágio, e fazendo com que o aluno possa ir além da prática, proporcionando com que ele procure entendê-la integralmente, inclusive o papel que as práticas corporais assumiram e assumem perante a sociedade.

O ponto crucial parece ser o acesso real e refletido á cultura corporal, através da prática efetiva das atividades, mas de uma prática capaz de aquisição e compreensão da expressividade da linguagem corporal, refletindo sobre o significado e os valores do mundo por ela representado e, também, construído. (OLIVEIRA, 2005, p. 97).

O jogo, por exemplo, é um conteúdo que tem que ser estruturado a partir de todos os seus significados, minimizando o enfoque sobre o estereótipo que a ele foi integrado, em que ao falarmos de jogo estamos falando somente de competição. Nesse direcionamento, “ o jogo, analisado a partir dos fundamentos teóricos da Cultura Corporal, caracteriza-se pela espontaneidade, flexibilidade, descompromisso, criatividade, fantasia e expressividade, representadas de diversas formas, próprias de cada cultura" (PARANÁ, 2006, p.60). 


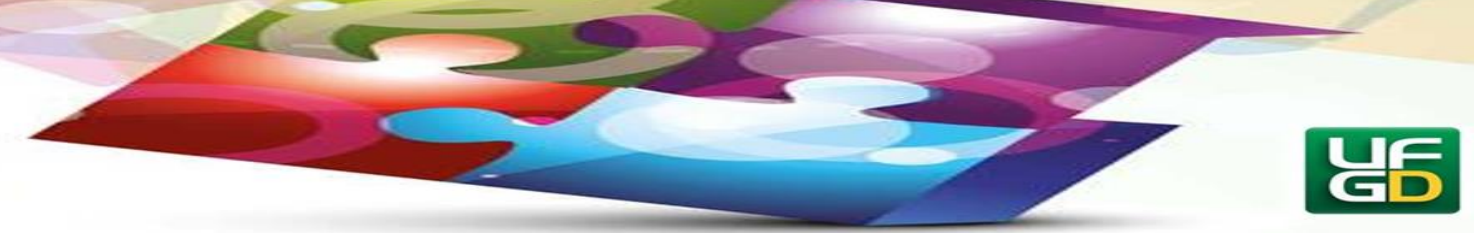

É a partir desse conceito que precisamos contextualizar o conteúdo para nossos alunos, para que eles mesmos criem suas próprias alternativas de efetuar qualquer juízo de valor a respeito do conteúdo em questão, e compreender que ele pode conceituar o jogo de várias outras formas não apenas como uma competição. Através da Cultura Corporal é possível essa reflexão, na proporção de estabelecer ao aluno um vasto campo de discussão acerca das questões impostas em volta não apenas de um simples jogo, mas que ele seja capaz de identificar os vários significados que uma sociedade pode estipular para o seu convívio como sujeito praticante nela.

Porém, um dos maiores problemas para a efetivação da Cultura Corporal na Educação Física escolar é o método como se dá a relação entre teoria e prática. Mesmo que professores demonstrem a preocupação com conteúdos relacionados à intervenção social e suas bases epistemológicas, a expectativa dos alunos é de que a aula seja agradável, um momento de lazer, normalmente ligado à prática de esportes, e isso se dá proveniente do propósito que foi durante tanto tempo imposto nas aulas em ser trabalhado apenas atividades práticas, formando um conceito nos alunos de que a aula de Educação Física é um momento praticar esportes e sair da sala de aula.

A função da Educação Física escolar, ao nosso ver, não é ensinar o Basquetebol, ou o Voleibol, ou o Handebol, ou o Futebol, mas utilizar atividades valorizadas culturalmente num dado grupo para proporcionar um conhecimento que permita ao aluno, a partir da prática, compreender, usufruir, criticar e transformar as formas de ginástica, as danças, as lutas, os jogos e os esportes, elementos da chamada Cultura Motora(ou Corporal, ou Física) (DAOLIO, 1995b, p.135).

Baseado nesse conceito é que temos que redimensionar a intervenção da Educação Física para uma reflexão significativa dos conteúdos pertencentes a cada modalidade, a Cultura Corporal se faz presente como um instrumento que vai proporcionar ao aluno o conhecimento sobre o surgimento das modalidades esportivas, quais foram suas modificações e influencias que fizeram com que sua prática viesse a ser o que é atualmente, podendo ser ressaltado a comercialização como um elemento extremamente influente no sentido de modificar a estrutura de uma modalidade esportiva, e isso tudo está integrado a proposta pedagógica da Cultura Corporal, que se faz pertinente para o entendimento do aluno em relacionar o quanto a 


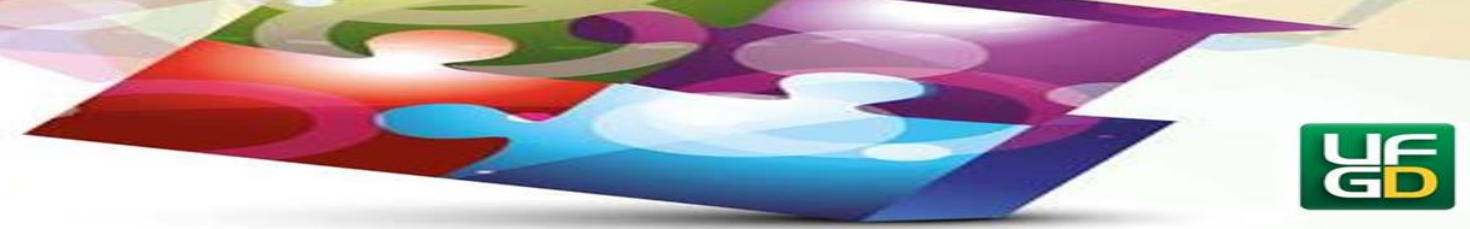

sociedade pode influenciar o comportamento de um individuo, ou na configuração de uma modalidade, seja ela esportiva ou não.

De maneira sucinta cabe citar ainda que a Cultura Corporal trata da interdependência dos cinco conteúdos (jogos, esporte, luta, dança, ginástica) citados e articulados com os grandes problemas sócio-políticos atuais, alguns deles são: papel sexual, saúde pública, deficiência e preconceitos raciais, condicionando ao aluno a capacidade de realizar

(...) uma reflexão pedagógica sobre o acervo das formas de representação do mundo que o homem tem produzido no decorrer da história, exteriorizadas pela expressão corporal: jogos, danças, lutas, exercícios ginásticos, esportes, malabarismo, contorcionismo, mímica e outros, que podem ser identificados como formas de representação simbólica de realidades vívidas pelo homem, historicamente criadas e culturalmente desenvolvidas." (COLETIVO DE AUTORES, 1992, p.38).

Cabe a Cultura Corporal mostrar um significado para toda e qualquer a ação ou movimento que o aluno realize, no sentido do aluno entender e refletir sobre essa ação, motivo pelo qual faz da Cultura Corporal uma ferramenta relevante de ser pautada no planejamento docente, considerando que podemos trabalhá-la juntamente com diversas outra áreas.

Passadas as reflexões sobre pensamento social brasileiro e a cultura corporal, abra-se espaços para a interligação de cultura corporal com o lazer, com a prática física, com a prática pedagógica e com outras linhas de entendimento para que a criticidade, seja o pensamento que nasça das mentes ávidas por cultura e conhecimento, formando novas dialéticas para Educação Física na sociedade. (MERLO, 2006, p.08).

O objeto de estudo apresentado nos faz perceber que ele mesmo nos proporciona a condição de transportar o conhecimento para os nossos alunos de variadas formas, e contemplando os mais diversos assuntos, todos amparados por um contexto histórico que auxiliará ainda mais o aluno no desenvolvimento da sua capacidade de entender e refletir sobre um determinado fenômeno, esse propósito não tem como objetivo excluir a prática de atividades 


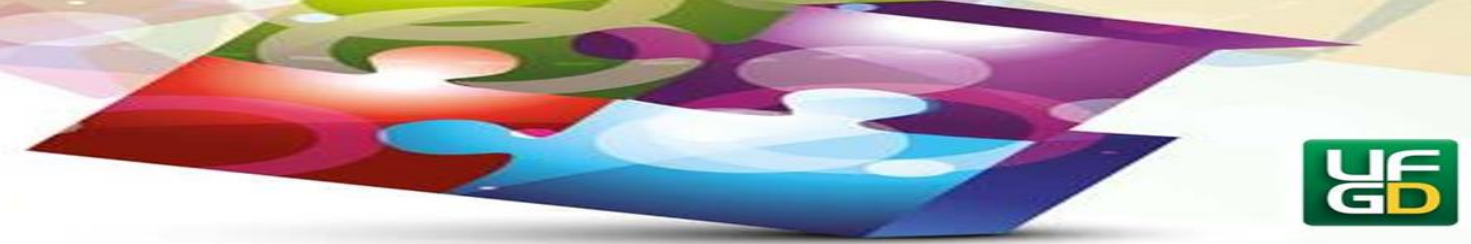

físicas das aulas, mas sim de apresentá-las de forma significativas, para que acima de tudo o aluno vá além da prática funcional, e passe a estabelecer significados e compreender valores atribuídos a essa prática.

A intenção destas reflexões foi somente a de alertar que os profissionais de educação física, por trabalharem com o homem através do seu corpo, estão trabalhando com a cultura impressa nesse corpo e expressa por ele. Portanto, mexer no corpo é mexer na sociedade da qual esse corpo faz parte. O profissional pode fazer isso de forma explícita, atento para as consequiências do seu trabalho, ou de forma implícita e inconseqüente. Parece-nos evidente tentarmos estar atentos e conscientes em relação ao papel do corpo na cultura. (Daolio, 1995a, p.27).

É a partir desse conceito que precisamos compreender a Educação Física como uma disciplina que trabalha diretamente com o corpo. Em consequência, temos que estar conscientes de que quando estamos falando de corpo, estamos ao mesmo tempo falando de cultura. É por esse motivo que a Cultura Corporal se faz relevante para o planejamento do professor, pois da o suporte no entendimento de toda a transformação e evolução do movimento, ancorada em um recorte teórico, não no sentido de excluir a prática, mas no sentido de entender o corpo como um elemento de cultura, buscando compreender todas as manifestações históricas, e trabalhando a prática e a teoria juntamente com a reflexão, pois é através do movimento que o aluno poderá refletir, criticar e até mesmo transformar tal movimento, baseado em um objeto de estudo que busque a compreensão e que oportunize dar sentido e significados para a sua prática corporal e do movimento, objeto de estudo este conhecido como Cultura Corporal.

\section{METODOLOGIA}

O trabalho de pesquisa foi dividido em algumas etapas, nas quais teve como tópicos primários a construção de uma breve introdução de qual foi à história da Educação Física em seu contexto geral. A partir dessa introdução, a apresentação do processo de evolução e transformação dessa disciplina. Decorrente disso acompanhamos quais são as possibilidades de 


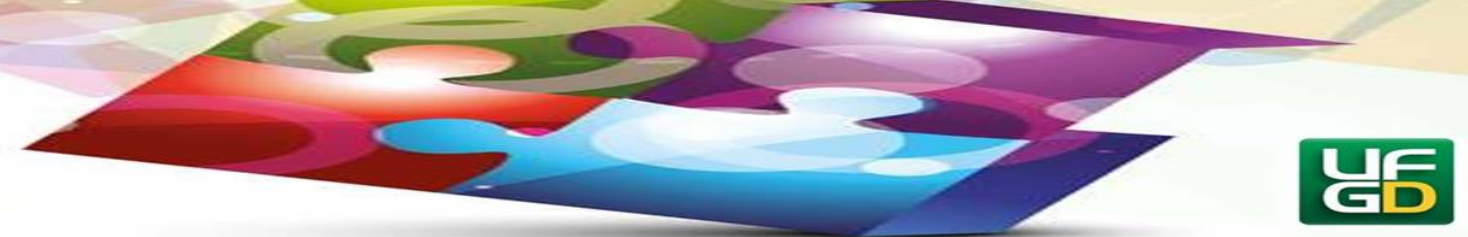

intervenção pedagógica que a cultura corporal proporciona para os planejamentos docentes. Tal trabalho foi realizado no período de tempo entre junho do ano de 2010 e setembro também do ano de 2010, o qual está compreendido como uma pesquisa documental, pois, sua produção é acerca de informações escritas e restrito apenas a documentos, tais como livros, artigos, entre outros, sendo que todas as informações são descritas em português, e o critério de seleção para a utilização do material foi determinado a partir da referência que tivesse problematizando a proposta de pesquisa em questão, como autores já conhecidos e que defendem a Cultura Corporal como objeto de estudo. A metodologia adotada para o desenvolvimento da pesquisa é de abordagem qualitativa, pois não compreendeu como objetivo a obtenção de resultados baseados em gráficos, e nem quantidade de sujeitos a serem observados.

\section{CONSIDERAÇÕES FINAIS}

A Educação Física assumiu durante muito tempo um papel biológico e funcional, em um primeiro momento em formar corpos para o trabalho, em um segundo momento formar corpos fortes para defender a pátria, não podemos esquecer também que nossa disciplina tinha como função na década de 1940 descobrir atletas para representarem nosso país em grandes competições esportivas.

Considerando esses aspectos, podemos compreender que a função da Educação Física historicamente era preparar o individuo para atender as necessidades impostas pela sociedade, e principalmente pelas classes dominantes.

Se atermos nossas atenções para o momento atual contemporâneo, precisamos voltar a intervenção pedagógica para elementos que visem formar o aluno para si mesmo, e capacitá-lo para o convívio social, na intenção de que o mesmo possa desenvolver conhecimento suficiente para interagir na sociedade com propriedade e consciente da sua intervenção social.

Para que o individuo atue na sociedade de forma que possa entender e compreender suas manifestações, é necessário acima de tudo que ele conheça todos os componentes históricos que a constituíram na forma como está apresentada atualmente, a partir de uma intervenção que busque resgatar o contexto de cada momento histórico pertinente a nossa disciplina. 
Se o principal objetivo da educação básica é formar seres críticos e participantes na sociedade a qual pertence, na condição de torná-los capazes de atuar em um meio com discernimento de todos os fenômenos que o constituem, é necessário contemplar em nossos planejamentos uma proposta pedagógica que vise à reflexão sobre tudo aquilo que influenciou nas ações da humanidade.

Por estarmos nos referindo a Educação Física, estamos trabalhando diretamente com o corpo e o movimento. Por esse fato não podemos desconsiderar que o corpo é um elemento capaz de transmitir cultura, e que é a cultura que fundamentou toda a existência humana.

Por isso, precisamos de uma proposta capaz de viabilizar ao aluno novas possibilidades de compreensão e intervenção acerca do movimento humano, na condição de apresentar aos alunos todas as transformações a que fomos submetidos durante a evolução da humanidade.

A Cultura Corporal compõe como principal aspecto a reflexão, voltado para as representações do movimento humano, esse fato faz dela um componente curricular extremamente relevante para as metodologias de ensino, pois, proporcionará ao aluno a bagagem suficiente de conhecimento para atuar em qualquer contexto social.

Pode-se concluir então, que a Cultura Corporal tem que ser uma ferramenta implantada e explorada na metodologia de ensino da Educação Física, por contemplar fatos pertinentes a realidade, proporcionar a sistematização e ampliação do conhecimento, e principalmente por aprofundar o conhecimento em bases que fundamentam a nossa existência. A partir disso estaremos formados pessoas que serão capazes de entender sua própria evolução e contribuir para que essa evolução não fique estagnada em um determinado ponto. A Cultura Corporal então através das discussões apresentadas se faz pertinente e relevante para ser implantada na proposta de ensino da Educação Física, pois é através dela que os alunos poderão dar segmento no seu processo de independência pessoal e também social.

\section{REFERÊNCIAS}

ASSIS DE OLIVEIRA, Sávio. Reinventando o esporte: possibilidades da prática pedagógica. - 2. Ed. - Campinas, SP: Autores Associados, 2005.

AZEVEDO, E. S. ; SHIGUNOV, V. . Reflexões sobre as Abordagens Pedagógicas da Educação Física. In: Viktor Shigunov e Alexandre Shigunov Net. (Org.). A Formação Profissional e a Prática Pedagógica em Educação Física. 1 ed. Londrina/PR: Midiograph, 2001, v. 1, p. -. 


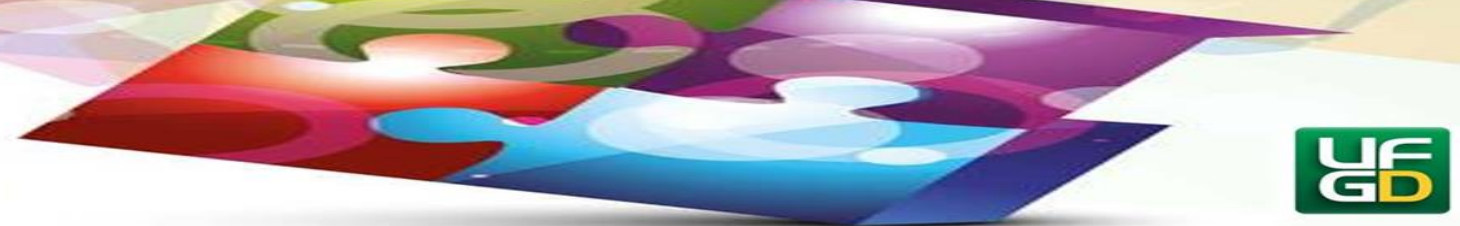

BRACHT, Valter. Aprendizagem social e Educação Física. Porto Alegre: Magister, 1992.

BREGOLATO, Roseli Aparecida. Cultura corporal da ginástica, coleção educação física escolar: no princípio de totalidade e na concepção histórico-crítico-social. $2^{\mathrm{a}}$ edição, São Paulo: Ícone, 2002.

COLETIVO DE AUTORES (1992). Metodologia do ensino de educação física. São Paulo: Cortez.

DAOLIO, J. . Os Significados do Corpo na Cultura e as Implicações para a Educação Física. Movimento (Porto Alegre), São Paulo, v. 2, n. 02, p. 24-28, 1995 a.

DAOLIO, J. Por uma educação física plural. Revista Motriz, v.1, n.2, p.134-136, dezembro/1995b.

MARCONI, Marina de Andrade; LAKATOS, Eva Maria. Metodologia do Trabalho Cientifico. $5^{\circ}$ edição, São Paulo: Editora ATLAS, 2003.

MELLO, A. S. Cultura Corporal: pressupostos, representações sociais e reflexões acerca dessa concepção pedagógica.. In: XIII Congresso Brasileiro de Ciências do Esporte, 2003, Caxambu/MG. XIII Congresso Brasileiro de Ciências do Esporte, 2003.

MERLO, T. E. ; TAVARES, S. F. . CULTURA CORPORAL E PENSAMENTO SOCIAL BRASILEIRO: Modelo contemporâneo e dialéticas. Conexões (UNICAMP), Campinas - SP, 2006.

PARANÁ. Diretrizes Curriculares da Rede Pública de Educação Básica do Estado do Paraná: Educação Física/ Secretaria do Estado da Educação - SEED, Paraná: 2008

PARANÁ. Livro Didático Público. Educação Física / vários autores. $2^{\mathrm{a}}$ edição. Curitiba: SEED, 2006.

SANTOS, Gilbert de Oliveira. Alguns sentidos e significados da capoeira, da linguagem corporal da educação física...Revista Brasileira de Ciências do Esporte, Campinas, v.30, n.2, p. 123-136, Autores Associados, janeiro 2009.

SOARES, Carmem Lúcia. Educação Física: raízes européias e Brasil. Autores Associados, $4^{a}$ edição, 2007, Campinas, São Paulo.

Data do envio do trabalho: 06/05/2019

Aprovado em: 09/10/2019

Publicado em: 18/12/2019 